\title{
Resolving Ethnic Relations in Vietnam: A Case in Lam Dong Province in the Central Highlands
}

\author{
Vu Kim Diem ${ }^{(1)}$, Nguyen Hoang Thien ${ }^{(2)}$ \\ (1), (2) Kien Giang University (KGU), Kien Giang Province, Vietnam \\ Email: vkdiem@vnkgu.edu.vn'; nhthien@vnkgu.edu.vn²
}

\begin{abstract}
The paper briefly presents the concept of ethnicity and nationality. Based on the definition and scope of the concept, the paper presents the characteristics of ethnic groups and analyzes the history of ethnic relations in Lam Dong. From these analyzes, the paper focuses on interpreting the importance of building ethnic relations in the process of industrialization and modernization in Lam Dong province: i) To create opportunities and conditions for ethnic groups in the province to cooperate and develop in all aspects, together successfully realize the cause of industrialization and modernization. ii) To build up ethnic relations so that the ethnic groups in the province can consolidate their mutual understanding and trust, thus avoiding conflict and tension leading to the danger of ethnic separateness, obstructing the process of industrialization and modernization.
\end{abstract}

Keywords: building ethnic relations, Lam Dong Province, the Central Highlands, Vietnam

\section{Introduction}

In the view of Marxism-Leninism on the issue of national relations and the practice of building and defending the Vietnamese fatherland as well as experience in handling issues of national relations in the world, the Party and State of Vietnam always deeply grasping the issue of ethnic relations is one of the issues of strategic importance of the Vietnamese revolution. Document of the XII National Congress of the Communist Party of Vietnam affirms: "National solidarity has a strategic position in our revolutionary cause. Continue to perfect mechanisms and policies to ensure equality, respect, solidarity, and harmonious settlement of relations between ethnic groups, helping each other develop the region's economy, culture and society. There are many ethnic minorities, especially in the Northwest, Central Highlands, South West, Central Coast" (Communist Party of Vietnam: 164).

In a multi-ethnic country, ethnic relations play an important role along with other relationships affecting the history of birth, existence and development of each nation. Historical fact has proven that the role of national relations and the impact of ethnic relations in a country is very large and comprehensive. In the process of building the country in the direction of industrialization and modernization, the relationship between ethnic groups plays a great role and has a great impact on the implementation and implementation of economic development goals. national society and society. Therefore, it is urgent to pay attention to, research, and properly realize the role of ethnic relations building in Lam Dong province, Central Highlands of Vietnam.

The research questions in this study will be:

Question 1: What is the current view of ethnicity and ethnic relations? 
Question 2: What is the importance of resolving the relationship between ethnic groups in Lam Dong province and the Central Highlands of Vietnam today?

\section{Literature Review}

The studies on ethnic issues and the relationship between ethnic groups in Vietnam in general and Lam Dong province in particular can be summarized as follows:

Some ethnic issues and national policy views of the Party and State of the Political General Department, Department of Thought - Culture, Publisher. People's Army, 1998, the book's content mentions the issue of ethnicity and ethnic relations in a nation (pre-capitalist period, capitalist period up to now); Ethnic Vietnam; the national policy of our Party and State in the Doi moi period. Marxism-Leninism and Ho Chi Minh's thought on the national issue of Nguyen The Thang, Publishing House. Labor, 1999, the author focuses on researching the issues of Marxism-Leninism's views, Ho Chi Minh's thought on ethnic issues and the lines and policies of the Party and State of Vietnam on the issue of people clan.

Studying the general theory of ethnic groups, the relationship between ethnic groups for socio-economic development, there is also the work National relations and national policy in socialism (through Soviet documents. of the Vietnam Academy of Social Sciences, Institute of Social Science Information, 1990, the author has analyzed urgent theoretical issues about ethnic relations, such as: relations between ethnic groups, ideological issues in the development of ethnic groups, the Party's national policy in current conditions, ethnic groups and the state, ethnic issues in the reform condition, discussing new political thinking in national issues, philosophical questions of theory and practice of national relations in socialism; Relations between ethnic groups in an ethnic country of Dang Nghiem Van, Publishing House. National Politics, Hanoi, 1993, the author explains the different views around ethnic issues and ethnic relations, the relationship between the ethnic community and the socio-political community in history. From there, analyze the process of formation and characteristics of the Vietnamese people and propose some basic contents and solutions to promote the development of ethnic minorities and mountainous people. in the renovation and general development of the Vietnamese nation.

Concerning this research direction, there is the work Ethnic issues and ethnic policy development orientation in the period of industrialization and modernization of the Institute for Ethnic and Mountainous Policy Research, Publishing House. National Politics, 2002. Content presents theoretical issues about national awareness, national policies of the Party and State. The basic orientations in population planning, speeding up the pace of economic development of goods in accordance with the characteristics of each region in order to promote industrialization and modernization. At the same time, to propose basic issues such as hunger eradication, poverty reduction, illiteracy eradication, improving people's knowledge, health care, consolidating the system of ethnic agencies, respecting and promoting the village. good cultural identity of the ethnic groups, soon stabilizing and improving the lives of ethnic minorities.

Next is the Construction and consolidation of the great national unity bloc in the Central Highlands, Publishing House. National Politics, Hanoi, 2008. The work has analyzed and clarified the solidarity tradition of ethnic groups in the Central Highlands through historical periods, the process of building and consolidating the great solidarity bloc of ethnic groups in Central Highlands in the democratic national revolution and socialism building, especially the doi moi period. At the same time, the author analyzes trends that appear in ethnic relations, from which proposing a number of solutions to contribute to completing guidelines, supplementing policies for ethnic minorities, building and strengthening the national unity bloc in the Central Highlands.

In addition, there are a number of research works of a number of authors published in the magazine such as: Bui Chi Kien, "The process of innovation and development in Lam Dong", 
The Communist Review, No. 6, 1995, p. .23-25; Bui Chi Kien with "Continuing to advocate for sedentarization and sedentarization in ethnic minority areas in Lam Dong province", Journal of Theoretical Research, No. 1/1995, pp.4-7; "Lam Dong invests in socio-economic development in ethnic minority areas" by Nguyen Hoai Bao, Communist Review, 2002, No. 21, 2002, p.43-46;...

\section{Research Methods}

Method and Data

To do the research, the author uses qualitative research methods and explanatory methods. Qualitative research method: Based on the theory and model from previous studies to collect information, then analyze the importance of building and developing relationships between ethnic groups in Lam Dong province. Synthetic, historical and dialectical methods are also used.

\section{Research results}

\section{Views on ethnicity and ethnic relations}

Ethnicity is a scientific concept that is still debated and has many ways to define and understand this concept. From the socio-political perspective, the concept of ethnicity can be understood in two meanings: First, in the sense of ethnic, ethnic is an ethnic community with the same language, history - origin, cultural life and ethnic self-awareness. In this sense, we have the ethnic Han, the Jewish people, the Kinh people... In the world today there are more than 3,000 ethnic groups, of which Vietnam has 54 ethnic groups; Second, in the sense of a nation, a nation is a stable community of people forming a nation, with a national territory, a unified economy, a common national language and intentions knowledge of our national unity, intertwined by our political, economic interests, cultural traditions and traditions of common struggle throughout the long history of building and defending the country. In this sense we have the Vietnamese people, the Chinese people, the French people... In the world today, there are more than 200 ethnic countries. Most countries in the world today are multiethnic. In this article, the author refers to ethnicity in the sense of ethnic people, used to refer to 54 ethnic groups of the nation of Vietnam.

According to Marxist philosophy, human society is not a sum of individual individuals but a community of people linked together by relationships in all areas of social life. In the process of producing material wealth, humans have established relationships with the natural world, human society and human thinking. Social relations are formed from the interaction and interaction of the subjects in the relationship and change according to historical circumstances. Therefore, human social relations are multifaceted, rich and complex such as class relations, ethnic relations, religious relations... In the work of Essay on Ludwig Andreas Feuerbach, Marx has asserts: "Human nature is not an inherent abstraction of a particular individual. In its realism, human nature is the sum of social relations" (Karl \& Friedrich, 1995: 11). On the basis of the ethnic concepts mentioned in the articles, understood in the ethnic sense; Derived from the standpoint of dialectical materialism and historical materialism when studying the problem, national relations are understood according to two levels as follows: In a narrow sense, ethnic relations are the interaction, mutual influence, bond, contribute to the regulation of the existence and development of each other within an internal ethnic group considered above all aspects of life: economic modes, language, customs, cultural traditions...; In a broad sense, national relations are the interaction between each other, influence each other, bind each other, contribute to the regulation of the existence and development of each other in a nation, this relationship is shown, dominated and bound by economic, political, cultural and social interests united within the social life of a country. Human society exists and develops according to objective laws and those laws are expressed through conscious human activity. In which, human activities and relationships have a huge 
decisive role in the development of social history. In a country with many ethnic groups, the national relationship is one of the basic social relations, having a decisive role in the existence and development of the country. Therefore, building relationships between ethnic groups is an objective indispensable thing. Stemming from the Marxist-Leninist point of view on national issues and the practice of building and defending the Vietnamese Fatherland, as well as experience in handling ethnic issues and national relations in the world, the Party and The State of Vietnam always considers the national issue and national relations building one of the issues of strategic importance of the Vietnamese revolution. Document of the XII National Congress of the Communist Party of Vietnam affirms "National solidarity has a strategic position in our revolutionary cause. Continue to perfect mechanisms and policies to ensure equality, respect, solidarity, and harmonious settlement of relations between ethnic groups, helping each other develop the region's economy, culture and society. there are many ethnic minorities, especially in the Northwest, Central Highlands, Southwestern and Central coastal regions" (Communist Party of Vietnam: 164). Currently, Vietnam is conducting the renovation, implementing the stage of accelerating the process of industrialization and modernization of the country to create a comprehensive and profound qualitative change in all areas of life. to bring the country to steady development to socialism. This is a great revolution in which the role of national relations is very important to the success of the renovation cause in Vietnam.

Lam Dong is one of the five provinces that make up the Central Highlands region, home to and living for more than 40 ethnic groups. Ethnic groups in Lam Dong have a tradition of solidarity and strong struggle in the history of building and defending the Central Highlands. Today, in the construction and defense of the Socialist Fatherland, all ethnic groups in Lam Dong need to consolidate, strengthen and further promote the strength of national solidarity, in order to successfully carry out the task. socio-economic development and political stability, national defense and security in Lam Dong province; contribute to the Central Highlands region and the whole country to successfully realize the common strategic goal of the great family of ethnic groups: industrialization and modernization of the country in the direction of socialist - rich people, country strong, democratic, fair, civilized.

Meanwhile, the Central Highlands region in general and Lam Dong province in particular has been and is a key area against hostile forces at home and abroad. In recent years, we have tried to take advantage of the ethnic diversity, the differences in economic, cultural and social life among ethnic groups, urgently propagating and provoking to divide and destroy the bloc. national solidarity - Lam Dong's core strength in the process of local industrialization and modernization.

Therefore, the research and deep awareness of the importance of building ethnic relations in Lam Dong in order to consolidate, strengthen and further promote the strength of ethnic solidarity, maintain the main security social order and safety, promoting socio-economic development, completing the industrialization and modernization in the province is an important and very urgent and meaningful task. both basic and urgent both in theory and practice.

Importance of building and developing relationships between ethnic groups in Lam Dong province in the Central Highlands of Vietnam today

Lam Dong is a mountainous province in the South of the Central Highlands, with an average altitude of $800-1,000 \mathrm{~m}$ above sea level with a natural area of 9,772.19 $\mathrm{km}^{2}$. The East borders on Khanh Hoa and Ninh Thuan provinces. The Southwest borders on Dong Nai province. The South and Southeast are bordered by Binh Thuan province. The North borders Dak Lak province. Lam Dong currently has 12 administrative units, including: Da Lat city, Bao Loc city and 10 districts The population of Lam Dong in 2015 was 1,273,088 people, population density was 130 people / km2, urban population. accounting for $38.97 \%$ and the 
rural area 61.03\% (website of General Statistics Office, 1979). Lam Dong is a land with many advantages in terms of natural resources, climate, soil... Therefore, from the past until now, apart from the indigenous people, it has attracted a large number of people from many ethnic groups. another place to settle down. Before the nineteenth century, ethnic minorities such as the Ma, K'ho, Churu... were indigenous people who had lived in this South Central Highlands for a long time. According to history, the population and composition of ethnic groups in Lam Dong have many changes.

The population is not only homogeneous ethnic minorities, but also many other ethnic minorities come to live. Through the fluctuations of historical circumstances, currently, Lam Dong has over 40 ethnic groups. The ethnic groups have unequal numbers of people, do not have separate territories but alternate with each other. In which, the Kinh accounts for the largest proportion of $77 \%$, the K'ho ethnic group $12 \%$, the Ma ethnic group $2.5 \%$, the Tay $2 \%$, the Nung $2 \%$, the Hoa $1.5 \%$, the Chu ru people $1.5 \% .$. the rest are other ethnic groups with the rate of less than 1\% (website of General Statistics Office, 1979). Due to the natural geographic conditions and the domination and exploitation of imperialist colonialism in history, the level of development in many aspects among ethnic groups in Lam Dong has a big difference, especially between Kinh people with other ethnic minorities. Like other ethnic groups in the Central Highlands and all over the country, ethnic groups in Lam Dong also have their own diverse and rich cultural identities. Ethnic minorities in Lam Dong, whether the majority or a minority, residents of indigenous ethnic groups or people who have migrated from other places are an unified and inseparable part of Lam Dong, of the region. The Central Highlands and the whole nation of Vietnam. The Kinh ethnic group is the majority group, plays a role as the nucleus of solidarity, mutual assistance and assistance to different ethnic groups to strive together for the common development of Lam Dong industrialization and modernization.

The history of building and defending Lam Dong has boldly emphasized the solid solidarity relationship between the ethnic groups here. During the long resistance war of the Vietnamese people against the French colonialists, the Japanese fascists and the American imperialists invaded, the peoples of Lam Dong have also merged into the vibrant atmosphere of the whole country, promoting solidarity relations, fighting vigorously from the very first days. In the 20-30s of the twentieth century, the struggle movement in Lam Dong against the French colonialism developed widely. Ethnic minorities united together to stand up to fight against arrest, arrest of soldiers, against the policy of land robbery of the French bourgeois... Typically the Mu Co movement at that time had gathered 10,000 people ethnic groups in the province joined against the French. In April 1930, the first Communist Party cell in Da Lat was established, the activities of ethnic minorities developed to a new step from spontaneity to self-consciousness. The movement of workers of ethnic groups in the plantations has developed deeply. Workers of the Kinh ethnic group act as the focal point, enlightenment and influence, attracting the ethnic minority workers to unanimously fight the oppression and exploitation of the French colonialists and the Japanese fascists. Strikes of ethnic workers in Cau Dat tea plantations (1936, 1937, 1938), Xidec firm (1938),... demanding a raise, paying debts for months of missing wages, improving working conditions. be fired without cause... mobilized thousands of people to participate. The French colonialists were terrified of the protests, had to compromise, and meet the legitimate demands of the workforce. The success and spread of strike activities in the province is a strong testament to the solidarity, mutual assistance and mutual help relationship between workers in particular and ethnic minorities in general against oppression, exploitation of the enemy.

Next was the Japanese coup d'etat to France, the struggle of ethnic minorities in the province was even more developed. The ethnic minorities mobilized each other not to pay taxes, do not work for Japan, and responded to all policies of the Viet Minh. The ethnic groups 
volunteered to join self-defense teams, participated in armed demonstrations against Japan, dug trenches, supplies for self-defense units to fight,... Especially, during this period, the peak of the wind The anti-Japanese movement was from August 22, 1945 to August 28, 1945, under the leadership of the Viet Minh Front, ethnic minorities in the whole province took to the streets to protest to take part in the insurrection to regain the government. the establishment of a new government. From 1954 onwards, after ousting France from Indochina, the American imperialists blatantly undermined the Geneva Agreement and jumped into South Vietnam to establish the government of Ngo Dinh Diem's henchmen. They devastated villages, looted food,... and gathered people into concentration camps, "strategic hamlets" along the edges of their military subdivisions. Ethnic minorities in Lam Dong joined forces and joined forces in the resistance war against the US invasion. In 1960 onwards, the struggle movement entered a new period with the direct and unified leadership of the Party and the support of the ethnic groups throughout the country. The army and people of all ethnic groups in the province united with one heart against the raid, cornered the people, established the "strategic hamlet" of the enemy, built and protected the revolutionary government right in the heart of the enemy. The first victories such as: La Oang, Bac Ruong, Da Xang, Di Linh, Bo Sar, Tan Rai,... motivated and enthusiastic to revolutionize the army and people of ethnic groups in the province. The pro-American government Ngo Dinh Diem increasingly saw the danger and growth of the revolutionary movement of the ethnic groups in the province. They strengthened their forces, equipped with many modern weapons and actively enforced the 10-59 law, implemented the policy of "prosecuting plus", "destroying plus" with the slogan rather "killing mistakes than omitting" for herds. oppressive movements, but all met with a fierce counterattack by the army and people of all ethnic groups. The people of all ethnic groups united, together they covered and nurtured the soldiers and built revolutionary bases throughout the area. In 1975, the army and people of ethnic groups in Lam Dong tightened their solidarity in turn to encircle, attack and destroy the enemy, liberating Bao Loc (March 28, 1975), Di Linh (March 29, 1975), Da Lat (April 3 1975) and the entire province contributed to the liberation of the South and the reunification of the country.

It should also be emphasized that, right from the time of the French colonization, the American imperialism invaded our country. They always identify the Central Highlands as a place that has a particularly important position in terms of economy, security and national defense that must be held. Therefore, on the one hand, they try to destroy and create friction in order to divide the solidarity and peaceful relationship of the peoples here. On the one hand, the French colonialists migrated the northern ethnic groups to Lam Dong and other Central Highlands provinces to have human resources for resource exploitation, economic production to serve the French bourgeoisie; on the other hand, they carry out Christian evangelization, confuse bourgeois people, provoke narrow nationalist thought of local ethnic minorities under the guise of "Upper Land of Montagnards", "Autonomous regions" to occupy Acquire resources and train minions. However, the enemy never reached his goal. National relations of solidarity, attachment and mutual assistance in production and fighting are still key. Later, the US imperialism, through the administration of Ngo Dinh Diem's henchmen, intentionally caused conflicts and conflicts between nations by implementing the large national policy "Trong Kinh contemptuous", cornering people to establish "hamlets. strategy", propagating Protestantism to easily rule and disrupt the revolutionary movement. The plot and actions of reactionary forces are to enslave, oppress and exploit the nations, and monopolize the Central Highlands into their colony. In the following years, the reactionary forces of Fulrism, which the US - Wei set up to carry out the anti-riots, demanded the establishment of "Degar Protestant State" in the Central Highlands provinces in the 2000s reactionaries could not carry out this plan in Lam Dong. They are defeated by the close 
solidarity of people of all ethnic groups in the province who believe in the leadership of the Party.

Considering the history of ethnic relations in Lam Dong from the past to the present, it is generally necessary to confirm that ethnic relations are stable. From an objective basis, ethnic relations in Lam Dong still have conflicts and friction arising in the development process. In addition, in the past as well as nowadays, the Central Highlands region in general and Lam Dong province in particular has been and is a key area against hostile forces at home and abroad. But ethnic relations still take place on the main feature of equality, solidarity, respect, mutual assistance and mutual assistance for mutual progress and development. This is an outstanding advantage and great achievement in ethnic relations in Lam Dong during the process of local protection, construction and development. Therefore, today Lam Dong continues to carry out industrialization and modernization, building and promoting ethnic relations in the province is of top importance.

Firstly, building ethnic relations to create opportunities and conditions for all ethnic groups in the province to cooperate and develop in all aspects, together successfully implement industrialization and modernization. Currently, the lives of ethnic groups in Lam Dong are still different in many aspects. This is a fact that greatly affects ethnic relations. Over the years, the Party and State and Lam Dong province have had a lot of attention and support policies and policies to gradually overcome the disparities in many aspects between ethnic groups. However, this is a long and enduring striving process. Ethnic groups in Lam Dong are governed by different geographical conditions and historical circumstances, so the level of development in all aspects is also different. Given that a province has more than 40 ethnic groups living in which more than $20 \%$ are ethnic minorities, the development of each ethnic group affects, impacts and contributes to the overall development of ethnic groups in Lam Dong, of the entire community of ethnic groups in Vietnam. In the new context of the country, the process of industrialization and modernization is being accelerated, building ethnic relations so that the ethnic groups in the province have the opportunity to cooperate and develop in all aspects weak. Ethnic relations are built and strengthened on the basis of equality, solidarity, respect and mutual assistance in the development process, so that all ethnic groups, especially ethnic minorities can advance. with the majority of ethnic groups, with other ethnic minorities.

Secondly, building ethnic relations so that ethnic groups in the province strengthen mutual understanding and trust, avoid causing conflicts and tension leading to the risk of conflict, ethnic separatism, obstructing the process. industrialization and modernization.

Ethnic issues and ethnic relations always contain sensitivity and complexity. In the world, since the second world war up to now, there have been many conflicts, most of which are related to ethnic issues and ethnic relations, linking ethnic issues with religious issue. Over the years, national and religious conflicts have continued to be tense in many regions: Southeast Asia (Philippines, Indonesia, Thailand, Myanmar- ma), South Asia (India, Pakistan, Pakistan), Middle East (Syria, Egypt), North Africa (Tunisia, Lebanon),... Ethnic conflicts are often very complicated, prolonged and difficult to resolve, leaving very heavy consequences, even turning into prolonged civil wars. The danger of national conflicts reaching their peak is the danger of national disintegration and secession. This is a major concern of every ethnic nation in today's world. The cause of these conflicts and contradictions is often derived from disagreements, tensions, friction, conflicts in national relations with economic, cultural, religious beliefs,...

Lam Dong is a province located in the Central Highlands, where many ethnic groups live. The ethnic situation in the world today is a profound lesson for Vietnam as well as Lam Dong to harmoniously handle ethnic relations in the development process. Historically, ethnic groups in Lam Dong have united with other ethnic groups in the country to expel foreign 
invaders, preserve national independence, protect the peace of the Central Highlands, contribute to victory. common country. Ethnic relations between ethnic groups are built, strengthened and increasingly stable throughout the process of building and developing Lam Dong. Today, in the new stage of socialism construction, along with the change of practical circumstances, the relations between ethnic groups must be more concerned and handled with comedy. The process of industrialization and modernization has given rise to new conditions that affect and affect ethnic relations in many directions and in many different directions. When the trend of national independence and autonomy is increasingly asserted, all ethnic groups have risen to assert themselves, and integrate and unify with the community of ethnic groups. This also makes the ethnic consciousness of each ethnic group strengthened. Therefore, policies related to ethnic issues and ethnic relations, if not implemented skillfully and satisfactorily, are likely to cause conflicts and conflicts. Along with the development process, the investment strategy in all aspects may still be irrational between regions, between ethnic groups, causing people to have insecurity, fear of assimilation and coercion.

\section{Conclusion}

In recent years, the ethnic situation in the Central Highlands in general and Lam Dong province in particular has been quite complicated, sometimes there has been a "hot spot". This is a sign that if you do not pay attention to build well and handle the ethnic relationship harmoniously, there will be many unpredictable dangers. It is also important to recognize that the Vietnamese Party and House in the process of implementing and resolving ethnic issues and ethnic relations have repelled and prevented "hot spots". However, the road ahead is still difficult and arduous, with stable and healthy ethnic relations to have favorable conditions for socio-economic development. Therefore, building ethnic relations to consolidate mutual understanding and trust, avoid causing conflicts and tension leading to the risk of conflict and national secession is indispensable. Increasing conflicts and conflicts between ethnic groups will become a destabilizing factor and affect the industrialization and modernization process of each locality as well as the whole country. Building ethnic relations for ethnic groups to increase mutual understanding, learn from each other and help each other in the development process. Building ethnic relations so that national conflicts and conflicts will be replaced by solidarity, respect, love and mutual trust, working together towards the common development goals of the province and the country family. If the national relations are stable and healthy on the basis of solidarity, love, respect and mutual support, the conflicts between nations will be resolved, and will not lead to tensions and conflicts. sudden. On the basis of mutual understanding, trust and respect, ethnic groups will have the faith to bring into play the internal strength of each nation, and to work in harmony with the different ethnic groups going forward together. And it is the mutual understanding and trust between the ethnic groups that will eliminate and eliminate the risk of ethnic division and separation.

The mutual understanding and trust between ethnic groups is one of the prerequisites for promoting the strength of each ethnic group as well as all ethnic groups in the province, is a great motivation for Lam Dong overcoming difficulties and challenges in the process of local socio-economic development, contributing to the country's construction in the direction of industrialization and modernization today.

Therefore, in the process of industrialization and modernization in Lam Dong province, the Central Highlands region and the whole country, building relationships between ethnic groups to be sustainable and develop to serve a common cause. Meaning is more important than ever.

\section{Acknowledgement}


We would like to express the anonymous research participants for their willingness to have taken part in this study. Additionally, our sincere gratitude should go to other relevant parties who have given comments and supported us during our study. Without their unconditional help and support, we would have never been able to finish this study.

\section{References}

1. Central Party Historical Research Committee. (1977). The Party's predecessor organizations. Hanoi.

2. Communist Party of Vietnam. (2000). Complete text (1930 - 1945), ep. 7. Hanoi: Political country.

3. Communist Party of Vietnam. (2016). Document of the 12 th National Congress of the Party. Hanoi: National Politics.

4. Geography of Lam Dong. (2001). National Cultural Publishing House, Hanoi.

5. Le, M. Q. (2009). Political thought of C. Marx, Ph.ngghen, V.I.Lenin and Ho Chi Minh. Hanoi: The political nation.

6. Lam Dong Statistical Office website, Lam Dong Statistical Yearbook 2015. Retrieved from http://cucthongke.lamdong.gov.vn/Default.aspx?Act=10\&IDNews=726

7. Mac, D. (editor, 1983), Ethnic issues in Lam Dong. Department of Culture and Information of Lam Dong province.

8. Nguyen, D. K. (1983). Ethnic groups in Vietnam (anthropological data). Hanoi: Social Sciences

9. Nguyen, D. T. (2020). Ho Chi Minh's creations on national liberation revolution and value era. Journal of Political Theory, No. 5

10. Nguyen, V. N. (2016). Solving the issue of national interests according to Ho Chi Minh ideology and implementing new jobs. Communist Review, No. 117.

11. Ho, C. M. (2000). Ho Chi Minh, Complete episode, ep.1. Hanoi: The Political Nation.

12. Ho, C. M. (2000). Ho Chi Minh, Complete episode, ep.2. Hanoi: The political nation.

13. Ho, C. M. (2000). Ho Chi Minh, Complete episode, ep. 5. Hanoi: The political nation

14. Karl, M., \& Friedrich, E. (1995). Entire episode, ep. 3. Hanoi: National politics.

15. Tran, D. T. (1975). Conversations about life activities of President Ho Chi Minh. Hanoi: The truth.

16. Tran, S. T. (1999). Ethnicity, People in Lam Dong Province, Hanoi: Statistics, Hanoi.

17. Vu, Q. H. (2011). Ho Chi Minh's thought on ethnic issues - discussion issues. Retrieved from https://khoalichsu.ussh.vnu.edu.vn/t-tng-h-chi-minh-v-vn -dans- my-vn-ban-lun / 